\title{
Robustly StABILIZING Regions OF PI CONTROLlerS PARAMETERS FOR SySTEMS WITH ADDITIVE UNCERTAINTY
}

\author{
Radek Matušů \& Roman Prokop
}
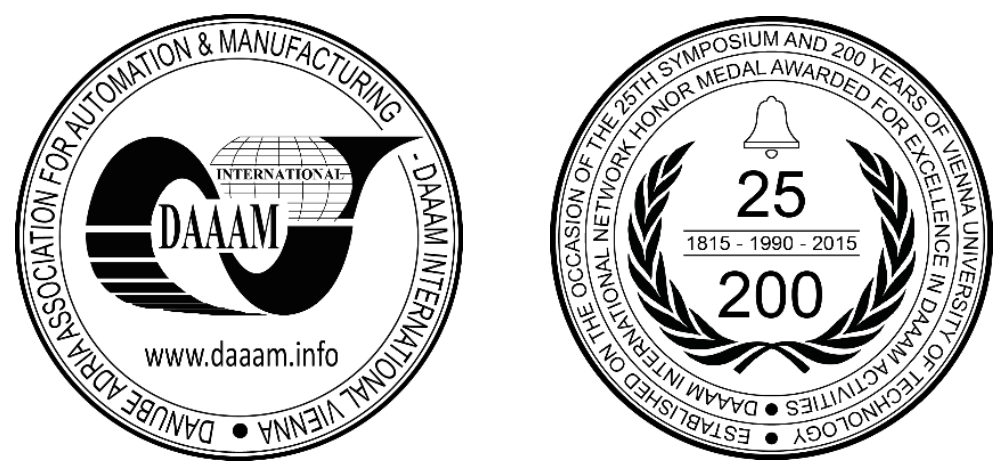

This Publication has to be referred as: Matusu, R[adek] \& Prokop, R[oman] (2018). Robustly Stabilizing Regions of PI Controllers Parameters for Systems with Additive Uncertainty, Proceedings of the 29th DAAAM International Symposium, pp.0176-0179, B. Katalinic (Ed.), Published by DAAAM International, ISBN 978-3-902734-20-4, ISSN 1726-9679, Vienna, Austria

DOI: $10.2507 / 29$ th.daaam.proceedings.025

\begin{abstract}
This paper deals with a technique for calculating the robustly stabilizing regions of parameters of Proportional-Integral (PI) controllers for Linear Time-Invariant (LTI) plants with unstructured additive uncertainty. The method applies the fundamental $\mathrm{H}_{\infty}$-norm-based robust stability condition for systems with additive uncertainty to compute the robust stability border pairs of P-I parameters. Subsequently, the obtained couples are plotted into the P-I plane, which defines a robust stability region. The effectivity of this graphical approach is demonstrated by means of the example.
\end{abstract}

Keywords: robust stabilization; pi controllers; additive uncertainty; unstructured uncertainty; robust stability regions

\section{Introduction}

A robust approach to control of various processes have become extremely popular in both theory and practical applications during the last more than four decades [1]. Despite the advances in many sophisticated control design techniques, the controllers with classical PI and PID structure are still widely used and incorporated in the majority of real control systems because of their relative simplicity, facile applicability, and the existence of the huge amount of tuning rules [2]. Thus, the issue of tuning PI(D) controllers is still topical, especially if they should cope with the systems under conditions of uncertainty.

The uncertainty, which somehow takes the mismatch between the real-life plant and its ideal mathematical model into consideration, can be incorporated in the LTI model by more approaches. Be reminded that from the viewpoint of robust control, only the "slow" (not significantly time-variant) changes of the model are allowed. Two basic groups of uncertain models for Single-Input Single-Output (SISO) systems use the parametric [3], [4], [5] or unstructured [6], [7], [8], [9], [10] uncertainty. Moreover, a classification that is more detailed exists for both main groups. Two most common subtypes of the unstructured uncertainty are represented by the multiplicative uncertainty [8], [9] and additive uncertainty [10]. One of the typical robust control tasks is to find such controller that guarantees control loop stability not only for one fixed (nominal) system but also for all possible members of the family of systems (described by some of the mentioned uncertain models). Such controller is called robustly stabilizing, and such control loop is then called robustly stable. 
The main aim of this paper is to present a method for computing the robustly stabilizing regions of parameters of PI controllers for LTI systems with additive uncertainty. The principal idea of the approach is to compute and plot the robust stability border pairs of P-I parameters on the basis of $\mathrm{H}_{\infty}$-norm-based robust stability condition [11], i.e., the robust stability border contour for $\left\|W_{A}(s) C(s) S_{0}(s)\right\|_{\infty}=1$ is depicted in the P-I plane and this contour divides the plane into robustly stabilizing and robustly non-stabilizing areas. The same problem, but for systems with multiplicative uncertainty, has been discussed previously in [9].

\section{Robust Stabilization of Systems with Additive Uncertainty by means of PI Controllers}

An LTI model with additive uncertainty is given by:

$$
G(s)=G_{0}(s)+W_{A}(s) \Delta_{A}(s)
$$

where $G(s)$ is the perturbed model, $G_{0}(s)$ represents a nominal model, $W_{A}(s)$ means a weight function (typically stable one) representing the uncertainty dynamics, and $\Delta_{A}(s)$ stands for the uncertainty, which can be described by an arbitrary (typically stable) function that fulfills $\left\|\Delta_{A}(s)\right\|_{\infty} \leq 1$.

The weight function $W_{A}(s)$ has to comply with the inequality:

$$
\left|G(j \omega)-G_{0}(j \omega)\right| \leq\left|W_{A}(j \omega)\right| \quad \forall \omega
$$

The closed loop that includes the plant with additive uncertainty (1) and the controller $C(s)$ is robustly stable if and only if [6], [7]:

$$
\left\|W_{A}(s) C(s) S_{0}(s)\right\|_{\infty}<1
$$

where $S_{0}(s)$ stands for a nominal sensitivity function:

$$
S_{0}(s)=\frac{1}{1+L_{0}(s)}=\frac{1}{1+C(s) G_{0}(s)}
$$

More information on the description and robust stability analysis of systems with unstructured additive uncertainty can be found, e.g., in [6], [7], [10].

Thus, the controller $C(s)$ that ensures the robust stability has to be designed in order to fulfill the basic condition (3). Under the assumption of well-known and extensively used PI controller, the region of robustly stabilizing parameters can be depicted in the P-I plane using the robust stability border P-I pairs [11], that is, the couples of P-I parameters which meet the condition:

$$
\left\|W_{A}(s) C(s) S_{0}(s)\right\|_{\infty}=1
$$

It defines the contour that divides the P-I plane into robustly stabilizing and robustly non-stabilizing regions.

\section{Example}

Consider the plant with unstructured additive uncertainty:

$$
G(s)=G_{0}(s)+W_{A}(s) \Delta_{A}(s) ; \quad\left\|\Delta_{M}(s)\right\|_{\infty} \leq 1 ; \quad G_{0}(s)=\frac{1}{s^{3}+2 s^{2}+4 s} ; \quad W_{A}(s)=\frac{0.09(7 s+1)}{s(0.5 s+1)^{4}}
$$

which was constructed in [10] from the original third order integrating plant with parametric uncertainty. Note that the robust stability condition (3) is valid even for the unstable (or integrating) plants as long as the number of right-hand (unstable) poles remains the same for each member of the family $G(s)$ [6], [7]. Suppose also that the plant (6) is connected in the feedback loop together with a PI controller:

$$
C(s)=\frac{k_{P} s+k_{I}}{s}
$$


The values of $\left\|W_{A}(s) C(s) S_{0}(s)\right\|_{\infty}$ for various combinations of parameters $k_{P}$ and $k_{I}$ are plotted in the Fig. 1. The grid for sampling the parameters was chosen as 0:0.1:5. The negative parameters were intentionally excluded from the calculations.

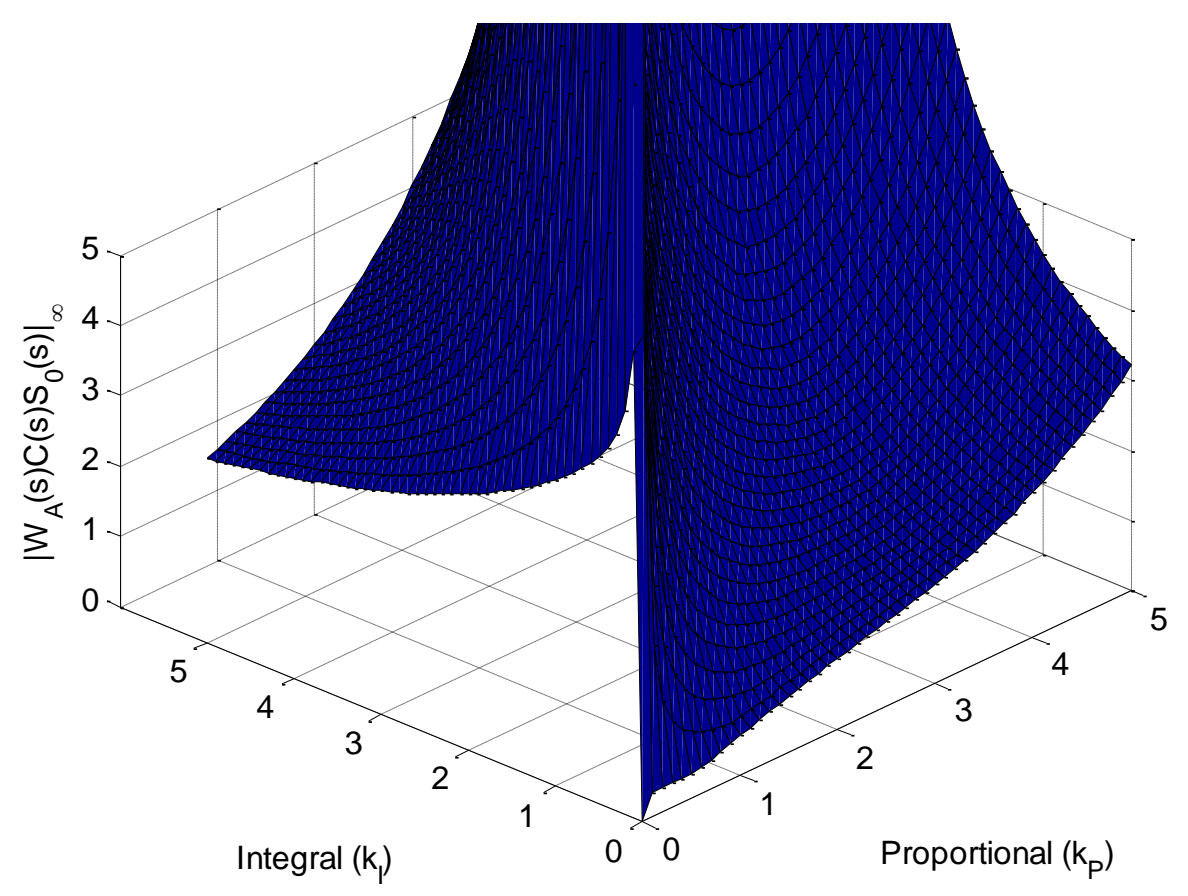

Fig. 1. Values of $\left\|W_{A}(s) C(s) S_{0}(s)\right\|_{\infty}$ for various combinations of parameters $k_{P}$ and $k_{I}$

Moreover, the Fig. 2 shows just the $2 \mathrm{D}$ contour for $\left\|W_{A}(s) C(s) S_{0}(s)\right\|_{\infty}=1$ which splits the P-I $\left(k_{P}-k_{I}\right)$ plane into the robustly stabilizing and robustly non-stabilizing area. Evidently, the robustly stabilizing region lies in the internal space of the obtained shape. It means that all possible PI controllers from this area will robustly stabilize the plant with unstructured additive uncertainty (6).

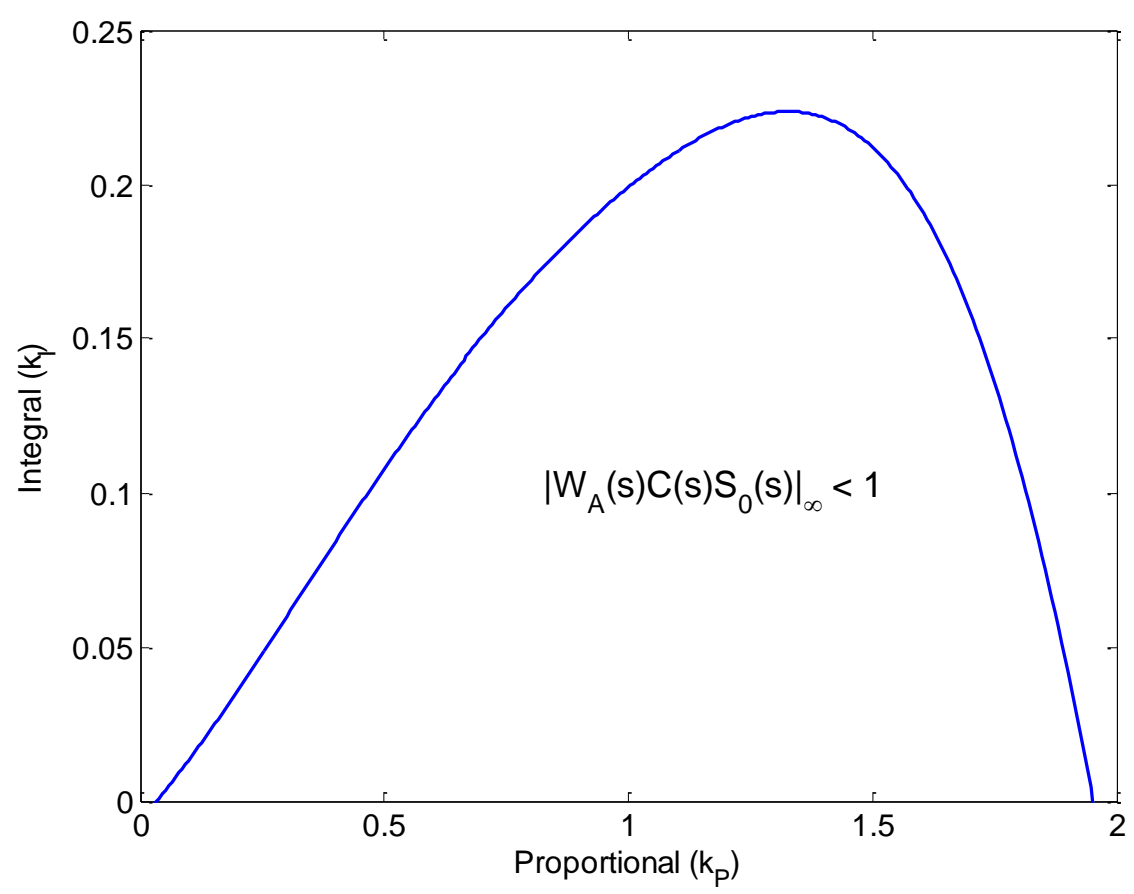

Fig. 2. Area of robustly stabilizing PI controllers 


\section{Conclusion}

The main goal of this contribution was to present a technique for calculating the robustly stabilizing regions of PI controllers parameters for LTI plants with unstructured additive uncertainty. The approach is based on computing and plotting the robust stability border pairs of P-I parameters by means of $\mathrm{H}_{\infty}$-norm-based robust stability condition. The effectivity of this graphical technique is demonstrated by using the illustrative example. The potential future research could involve not only robust stability but also some performance specifications.

\section{Acknowledgments}

This work was supported by the Ministry of Education, Youth and Sports of the Czech Republic within the National Sustainability Programme project No. LO1303 (MSMT-7778/2014).

\section{References}

[1] Safonov, M. G. (2012). Origins of robust control: Early history and future speculations. Annual Reviews in Control, Vol. 36, No. 2, pp. 173-181

[2] O’Dwyer, A. (2009). Handbook of PI and PID Controller Tuning Rules (3rd Edition), Imperial College Press, London, UK

[3] Bhattacharyya, S. P. (2017). Robust control under parametric uncertainty: An overview and recent results. Annual Reviews in Control, Vol. 44, pp. 45-77

[4] Barmish, B. R. (1994). New Tools for Robustness of Linear Systems, Macmillan, New York, USA

[5] Matušů, R. (2016). Robust Stabilization of a Continuous Stirred Tank Reactor Model, Proceedings of the 27th DAAAM International Symposium, Vienna, Austria, pp. 147-150

[6] Skogestad, S. \& Postlethwaite, I. (2005). Multivariable Feedback Control: Analysis and Design. John Wiley and Sons, Chichester, UK

[7] Doyle, J.; Francis, B. \& Tannenbaum, A. (1992). Feedback Control Theory. Macmillan, New York, USA

[8] Matušů, R.; Şenol, B. \& Yeroğlu, C. (2017). Linear systems with unstructured multiplicative uncertainty: Modeling and robust stability analysis. PLOS ONE, Vol. 12, No. 7, pp. 1-21

[9] Matušů R. (2019): Calculation of Robustly Stabilizing PI Controllers for Linear Time-Invariant Systems with Multiplicative Uncertainty. In: Advances in Intelligent Systems and Computing (Vol. 860) - Intelligent Systems in Cybernetics and Automation Control Theory, Silhavy, R., Silhavy P., Prokopova Z. (Eds.), pp 259-263. Springer International Publishing AG, Switzerland, Cham

[10] Matušů, R. \& Şenol, B. (2018). Description and Analysis of Systems with Unstructured Additive Uncertainty. In: Advances in Intelligent Systems and Computing (Vol. 661) - Computational Methods in Systems and Software 2017, Vol 1: Cybernetics Approaches in Intelligent Systems, Silhavy, R., Silhavy P., Prokopova Z. (Eds.), pp. 1-9. Springer International Publishing AG, Switzerland, Cham

[11] Kučera, V. (2001). Robust Controllers (Robustní regulátory). Automa, Vol. 7, No. 6, pp. 43-45. (In Czech) 